would have resembled "animal cunning" rather than "the kind of intuitive reasoning that we associate anthropomorphically with the term" (p. 112). This assertion is lame; having explored the consequences of the initial premise as far as he does, it is a pity that Dixon baulks at the final hurdle.

Another flaw of the book is that reproductive physiology is treated rather vaguely, at least from my own (mammalian) perspective. But such criticism could be misplaced. Our own self-esteem as mammals demands that much - perhaps too much - importance is placed on higher mammalian specializations in the great scheme of things. Dixon's book is well in tune with current trends in evolutionary palaeontology, in which mammals owe their place as much to historical accident as to any inherent design superiority over dinosaurs.

Only one mammal is described in detail, a rat-like aquatic placental, which is probably not very different from the earliest eutherians. Monotremes and marsupials do exist in Dixon's scheme, but apart from a bald statement of the fact in a figure, they are mentioned no more; all the familiar niches for large marsupials in Australasia are occupied by dinosaurs. Birds, likewise, get little attention. Although they are referred to frequently as successful aerial specialists along with the pterosaurs, only two species are mentioned in particular. Both are flightless. The constant bracketing of birds and pterosaurs would, I think, have been better accompanied by more consideration of how the ecologies of birds and pterosaurs differ and of why excessive competition between them is thereby avoided. But as with mammals, the birds should be seen as a reptilian offshoot rather than a group deserving class status. If the asteroid missed, the problems of reptile paraphyly would never have arisen, because birds and mammals would have had the same rank as any other amniote subgroup; and cladists would have had much less to talk about.

The final irony is that Dixon may not be very far off the mark, because many of his creations could well have trodden the Earth, or flown in the skies above it, during the Mesozoic. The fossil record is so poor that we can only know of a tiny fraction of the number of dinosaur species that existed. Animals living in most habitats, especially in areas of net erosion such as mountains, fossilize poorly. Dixon's "balaclav" (an alpine, yeti-like hypsilophodont, shown on the previous page) or "mountain leaper" (a fluffy warm-blooded coelurosaur that darts from pinnacle to pinnacle) could very well have existed outside the two-dimensional confines of his book.

Henry Gee is on the editorial staff of Nature.

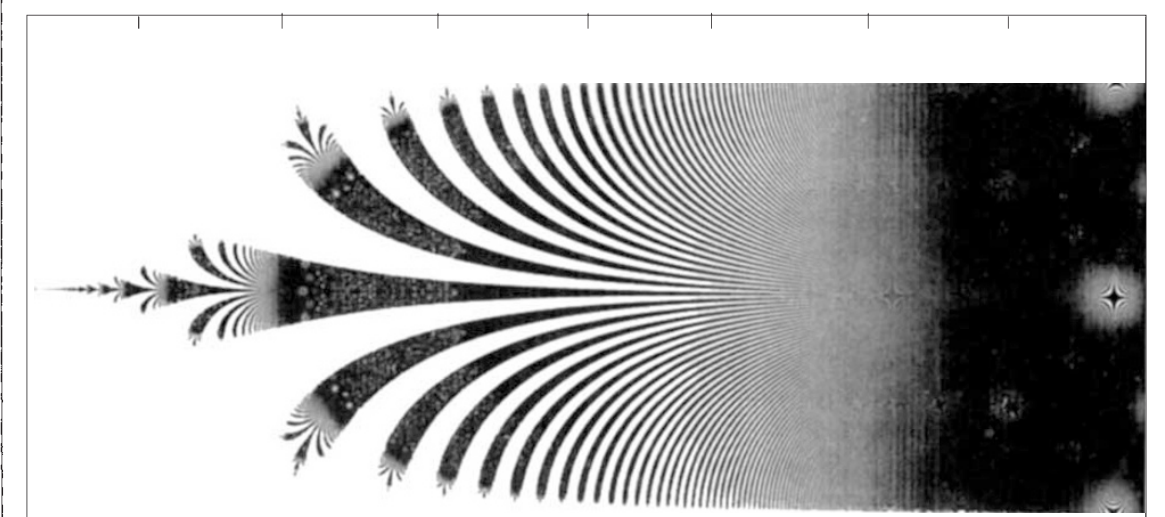

Infinite wisdom - fractal patterns of surprising complexity can be produced using simple iteration schemes on a microcomputer. Here the Julia set of the function $\frac{1}{\mathrm{e}} \mathrm{e}^{\mathrm{z}}$ is plotted in the complex plane. Points are coloured black if their path, or 'orbit', through the complex plane, determined by the iteration process $\mathrm{Z}_{\mathrm{n}+1}=\frac{1}{\mathrm{e}} \mathrm{e}^{\mathrm{Z}_{\mathrm{n}}}$ eventually escapes to infinity. The orbits of white points, however, all tend to the fixed point 1 . The picture is taken from The Science of Fractal Images edited by Heinz-Otto Peitgen and Dietmar Saupe. Publisher is Springer-Verlag, price $D M 68, £ 23, \$ 34$.

\section{Founding father}

\section{Robert Temple}

Theophrastean Studies: On Natural Science, Physics and Metaphysics, Ethics, Religion and Rhetoric. Edited by William W. Fortenbaugh and Robert W. Sharples. Transaction Books, New Brunswick, New Jersey/Clio Press, Oxford: 1988. Pp. 348. $\$ 49.95, £ 36.75$.

THEOPHRASTUS of Eresus in Lesbos was a younger friend of Aristotle, and they were students at Plato's Academy together. After Plato's death, Theophrastus became Aristotle's chief assistant in a massive programme to study the whole of nature, Aristotle taking animals as his subject and Theophrastus taking plants. They thus became the 'fathers' of zoology and botany, respectively, and their works followed a common plan. As R.W. Sharples puts it, they both saw "the natural world as in principle the object of a single, unified enquiry". After Aristotle's death in $323 \mathrm{BC}$, Theophrastus became the head of their school, the Lyceum, at Athens, where he had over 2,000 students.

Lists of his works by later librarians at Alexandria give more than 270 titles. Over 1,000 fragments of these have been gathered, edited and translated by the International Theophrastus Project and will be published within the next few years. The contributors to this volume are leading members of the project, and this is the volume intended to act as an introduction to the forthcoming fragments. (A text and translation of Theophrastus's Meteorology discovered in a Maharajah's library in India by Hans Daiber will appear as a separate volume.)

The book is not fully accessible to readers without some knowledge of Greek philosophy and philosophical terminology. But it has an importance far exceeding its forbidding presentation. The attention given to Theophrastus over the past decade, reaching its culmination here, makes possible for the first time a proper understanding of the methods, aims and achievements of Aristotle in his scientific works. In their biological writings, both Aristotle and Theophrastus are now seen to have avoided trying to construct a taxonomy. Their approach to understanding nature was entirely different, their joint efforts being directed towards discovering natural causes by a method derived from Aristotle's theories of logic, and which sought to elucidate and identify differences of distinctive features in the widest possible general classes. Their works were neither natural histories nor taxonomic enquiries, and until today a true appreciation of their intent has been entirely lacking. Historians of science will have to grapple with the bizarre implications of these findings, for we have here nothing less than the revelation that Western science emerged originally from systematic concepts and methodologies wholly different than had been thought until now.

One of the best contributions is by Alan Gotthelf, co-editor with James Lennox of another seminal work on the subject, Philosophical Issues in Aristotle's Biology (Cambridge University Press, 1987). Theophrastean Studies also portrays Theophrastus as a founder of ecology, student of pharmacology and historian of religion, and together the two books are of the greatest possible importance for those studying the roots of Western science.

Robert Temple, Hill House, Sutton Mallet, Bridgwater, Somerset TA7 9AW, UK, is author of, among other books, Conversations with Eternity, a comparative study of ancient protoscience (Hutchinson, 1984). 